\title{
Evaluasi Cadangan Karbon Tanah pada Beberapa Tipe Penggunaan Lahan Kering di Kecamatan Blang Bintang Kabupaten Aceh Besar
}

\author{
(Evaluation of Soil Carbon Reserves in Several Types Use of Drylands in Blang \\ Bintang Aceh Besar)
}

\author{
Asmi Susanti ${ }^{1}$, Munawar Khalil ${ }^{1}$, Sufardi $^{1 *}$ \\ ${ }^{1}$ Program Studi Ilmu Tanah, Fakultas Pertanian, Universitas Syiah Kuala \\ *Corresponding author: sufardi_usk@unsyiah.ac.id
}

\begin{abstract}
Abstrak. Tanah merupakan sumber daya penting bagi kehidupan makhluk hidup di muka bumi. Melalui penggunaan tanah untuk aktivitas pertanian dan produksi biomassa, sumber daya tanah dapat menghasilkan sumber pangan, pakan, sandang, papan dan bio-energi yang dapat mendukung kehidupan makhluk hidup (Utomo et al. 2016). Karbon merupakan salah satu unsur terpenting dalam ekosistem, hampir semua kehidupan makhluk hidup di permukaan bumi tergantung pada karbon. Studi tentang simpanan karbon tanah telah menjadi perhatian dalam rangka menilai kualitas tanah akibat aktivitas pertanian yang cenderung menyebabkan degradasi tanah. Penentuan karbon tanah diawali dengan pengambilan sampel tanah dilapangan dan selanjutnya dilakukan analisis C-organik di laboratorium dan terakhir dilakukan pengolahan data dengan menggunakan rumus yang mengacu pada Standarisasi Nasioanal Indonesia tahun 2010. Hasil yang didapat kemudian dikalkulasikan kedalam luasan hektar dan dibandingkan antara beberapa penggunaan lahan yang ada. Pada penelitian ini Persen Karbon $(\% \mathrm{C})$ tanah tergolong dari kriteria sangat rendah hingga tinggi yaitu berkisar antara 0,15-3,40\%. Dari tujuh tipe penggunaan lahan, potensi karbon tanah di hutan tanaman industri memiliki nilai yang paling tinggi yaitu 151,58 ton ha ${ }^{-1}$ dan semak belukar 44,82 ton $\mathrm{ha}^{-1}$ yang memiliki nilai yang terendah.
\end{abstract}

Kata kunci: Evaluasi, karbon, tanah, cadangan, lahan kering

\begin{abstract}
Land is an important resource for the life of living things on earth. Through the use of land for agricultural activities and biomass production, land resources can produce sources of food, feed, clothing, shelter and bio-energy that can support living things (Utomo et al., 2016). Carbon is one of the most important elements in the ecosystem, almost all living things on the earth's surface depend on carbon. The study of soil carbon storage has become a concern in order to assess soil quality due to agricultural activities that tend to cause soil degradation. Soil carbon determination begins with soil sampling in the field and then C-organic analysis is carried out in the laboratory and finally data processing is carried out using a formula that refers to Indonesian National Standardization in 2010. The results obtained are then calculated into hectares and compared between several land uses there is. In this study, the Carbon Percent (\% C) of the soil was classified from very low to high criteria, which ranged from 0.15 to $3.40 \%$. Of the seven types of land use, the potential for soil carbon in industrial plantations has the highest value, namely 151.58 tonnes ha ${ }^{-1}$ and shrubs 44.82 tonnes ha${ }^{1}$ which have the lowest value.
\end{abstract}

Keywords: Evaluation, carbon, reserved, dryland

\section{PENDAHULUAN}

Tanah merupakan sumber daya penting bagi kehidupan makhluk hidup di muka bumi. Melalui penggunaan tanah untuk aktivitas pertanian dan produksi biomassa, sumber daya tanah dapat menghasilkan sumber pangan, pakan, sandang, papan dan bio-energi yang dapat mendukung kehidupan makhluk hidup (Utomo et al., 2016). Tanah juga merupakan tubuh alam yang berinteraksi langsung dengan lapisan atmosfer. Atmosfer bumi mengandung nitrogen, oksigen, karbon dioksida, uap air dan gas-gas lainnya. Melalui ruang pori, tanah mampu mengalirkan dan melepaskan gas-gas ke atmosfer. Berkaitan dengan isu perubahan iklim, emisi gas $\mathrm{CO} 2$ dari dalam tanah menjadi penting karena akan mempengaruhi gas rumah kaca di atmosfer (Brady dan Weil, 2008). Karbon merupakan salah satu unsur 
terpenting dalam ekosistem, hampir semua kehidupan makhluk hidup di permukaan bumi tergantung pada karbon. Karbon merupakan unsur pembangun bahan organik, karena sebagian besar (58\%) bahan kering tanaman terdiri dari bahan organik (BO). Karbon organik (C-organik) yang ada dalam BO telah lama dikenal sebagai salah satu penciri kesuburan tanah dan lahan produktif. Sebaliknya, tanah merupakan tempat pencadangan karbon terbesar dalam ekosistem darat yang berperan penting dalam siklus karbon global. Setengah dari jumlah karbon yang diserap tanaman masuk ke dalam tanah melalui sisa tanaman (serasah), akar tanaman yang mati dan organisme tanah lainnya yang akan mengalami dekomposisi sehingga terakumulasi dalam lapisan tanah (Ruddiman, 2007).

Indonesia memiliki berbagai macam penggunaan lahan, mulai dari yang paling ekstensif misalnya agroforestri kompleks yang menyerupai hutan, hingga paling intensif seperti sistem pertanian semusim monokultur (Syam'ani et al., 2012). Jumlah C-organik setiap penggunaan lahan berbeda-beda, tergantung pada keragaman dan kerapatan tumbuhan yang ada, jenis tanahnya serta cara pengelolaannya. Perubahan penggunaan lahan (land use) dan perbedaan pola tanam dapat mempengaruhi jumlah karbon tanah. Konversi hutan menjadi lahan pertanian menyebabkan penurunan jumlah C-organik tanah. Demikian pula, pola tanam monokultur dan rotasi dapat menyebabkan perbedaan jumlah C-organik tanah. Simpanan karbon pada suatu lahan menjadi lebih besar apabila kondisi kesuburan tanahnya baik, atau jumlah karbon yang tersimpan di atas tanah (biomasa tanaman) ditentukan oleh besarnya jumlah karbon tersimpan di dalam tanah (C-organik) (Hairiah et al., 2007).

Secara geografis kabupaten Aceh Besar terletak antara $5^{\circ}, 2^{\prime}-5^{\circ}, 8^{\prime}$ Lintang Utara dan 95 $, 80^{\prime}-95^{\circ}, 88^{\prime}$ Bujur Timur (Pemerintah Kabupeten Aceh Besar, 2016). Penggunaan lahan di Aceh sangat beragam khususnya di Kabupaten Aceh Besar Laporan tentang evaluasi cadangan karbon tanah di Kabupaten Aceh Besar belum diketahui secara jelas, stok karbon tanah hutan dan tanah pertanian atau kebun sangat penting untuk dikaji lebih jauh terkait upaya mitigasi terhadap perubahan iklim, hal ini penting bagi pengelolaan pertanian berkelanjutan serta pelestarian lingkungan.

Penelitian ini bertujuan untuk menganalisis dan mengestimasi cadangan karbon tanah pada berbagai tipe penggunaan lahan kering di Kecamatan Blang Bintang Kabupaten Aceh Besar.

\section{METODE PENELITIAN}

Penelitian difokuskan pada beberapa titik observasi lapangan pada beberapa tipe penggunaan lahan kering di Kecamatan Blang Bintang Kabupaten Aceh Besar. Selain di lapangan, penelitian juga dilakukan di Laboratorium Penelitian Tanah dan Tanaman Fakultas Pertanian Universitas Syiah Kuala.

\section{Pengambilan Sampel Tanah}

Pengambilan sampel tanah di lapangan dilakukan pada setiap titik pengamatan jenis penggunaan lahan di lahan kering Kecamatan Blang Bintang Kabupaten Aceh Besar, untuk membandingkan kandungan karbon pada jenis vegetasi/penggunaan lahan maka disetiap pengunaan lahan diambil masing-masing 2 (dua) sampel tanah komposit pada kedalaman 0-5 $\mathrm{cm}, 5-10 \mathrm{~cm}, 10-20 \mathrm{~cm}, 20-30 \mathrm{~cm}, 30-70 \mathrm{~cm}$ dan 70-100 cm, untuk dianalisis kandungan karbon yang dilaksanakan di laboratorium. Adapun tata cara pengambilan sampel tanah dilapangan, langkahnya sebagai berikut: 
a.

b. Pengambilan sampel karbon tanah

(1) Pada setiap pengambilan sampel tanah dibuat minipit dengan ukuran panjang $\mathrm{x}$ lebar $\mathrm{x}$ dalam $(50 \times 50 \times 100 \mathrm{~cm})$ (2) Sampel tanah diambil pada sisi utara dan timur sesuai kedalaman yang telah ditentukan, namun apabila telah ditemukannya bebatuan pada lapisan tanah, maka penggalian dicukupkan dan sampel tanah diambil berdasarkan kedalaman yang ada (3) Pengambilan sampel tanah berdasarkan kedalaman 0-5 cm, 5-10 cm, 10-20 cm, 20-30 $\mathrm{cm}, 30-70 \mathrm{~cm}$ dan 70-100 cm (merujuk kepada panduan SNI 2010) (4) Pengambilan sampel tanah dilakukan dengan meletakkan plastik didalam lubang minipit untuk menampung sampel tanah yang diambil berdasarkan kedalaman yang telah ditentukan (5) Sampel selanjutnya dimasukkan dalam kantong sampel dan ditulis label.

\section{c. Pengambilan Sampel Bulk Density}

(1) Dibersihkan lahan pada setiap penggunaan lahan dari akar, batuan, rumput dan semak yang mengganggu (2) Ring diletakkan pada titik pengambilan contoh tanah disetiap penggunaan lahan (3) Ring sampel ditekan dengan tangan atau injakan kaki sehingga sebagian ring sampel terbenam ketanah (4) Selanjutnya diambil salah satu ring dan diletakkan diatas ring pertama (5) Diletakkan alas papan diatas ring yang kedua dan papan dipukul hingga ring sampel terbenam seutuhnya (6) Diambil ring sampel dengan cara menggali tanah disekeliling ring dan dikeluarkan dengan hati-hati (7) Dibersihkan dengan ring sampel dari tanah yang berlebihan dengan menggunakan pisau tajam, kemudian ditutup menggunakan penutup (cup) ring sampel dan dimasukkan ke dalam kotak sampel (8) Ring sampel diambil pada kedalaman top soil dan sub soil.

\section{Analisis Laboratorium}

Analisis bulk density

Analisis bulk density atau berat volume tanah menggunakan sampel tanah yang ada pada ring sampel, berikut adalah tata cara analisis bulk density, langkahnya yaitu: Ditimbang berat basah sampel tanah beserta ring, selanjutnya dimasukkan ke dalam oven pada suhu 105 oC selama minimal 48 jam, setelah kering, diambil tanah bersama ring dari dalam oven dan didinginkan di dalam desikator, setelah dingin, ditimbang sebagai berat sampel kering oven, ring sampel dibuang tanahnya dan dibersihkan, kemudian ring ditimbang sebagai berat ring sampel, kemudian ditentukan bobot tanah kering oven tanpa ring, nilai bulk density diperoleh dari pembagian nilai tanah kering oven dengan volume dari ring sampel.

Analisis C-organik

Analsisi karbon organik tanah dilakukan dengan menggunakan metode Walkey dan Black menggunakan panduan analisis Balai Penelitian Tanah (2005), caranya adalah dengan mereaksikan 0,5 g sampel tanah halus $(<0,5 \mathrm{~mm})$ dengan $5 \mathrm{ml}$ larutan $\mathrm{K} 2 \mathrm{Cr} 2 \mathrm{O} 7$ dan $10 \mathrm{ml}$ $\mathrm{H} 2 \mathrm{SO} 4$ di atas hotplate. Setelah dingin ditambahkan $5 \mathrm{ml} \mathrm{H} 3 \mathrm{PO} 4$ dan $50 \mathrm{ml}$ akuades, kemudian didiamkan beberapa saat. Setelah itu, dititrasi dengan larutan FeSO4 0,025 M menggunakan buret hingga berubah menjadi warna hijau bening dan dicatat volume larutan FeSO4 yang terpakai. Kandungan karbon organik tanah dihitung dari selisih terhadap jumlah volume larutan FeSO4 yang terpakai sampel dengan yang digunakan untuk blangko (tanpa tanah). Perhitungannya menggunakan rumus sebagai berikut: 
$\% \mathrm{C}=(\mathrm{b}-\mathrm{s}) /(\mathrm{b} / \mathrm{W} \times \mathrm{M}) \times 3$

Keterangan:

$\% \mathrm{C}$ : Persen $\mathrm{C}$ organik tanah

b : Nilai Titrasi Blangko

s : Nilai Titrasi Sampel

W : Berat Sampel

M : Faktor Koreksi

Perhitungan Densitas Karbon

Besarnya kandungan karbon yang terdapat di dalam tanah yaitu dengan mengalikan beberapa parameter yang diamati. Perhitungan densitas karbon tanah dilakukan dengan menggunakan rumus berikut (BSN, 2011) :

$\mathrm{Ct}=\mathrm{Kd} \times \rho \times \% \mathrm{C}$ organik

Keterangan:

$\mathrm{Ct} \quad$ : densitas karbon tanah, dinyatakan dalam gram $(\mathrm{g} \mathrm{cm}-2)$

$\mathrm{Kd} \quad:$ kedalaman contoh tanah, dinyatakan dalam sentimeter $(\mathrm{cm})$

$\rho \quad$ : kerapatan lindak (bulk density), dinyatakan dalam gram persentimeter kubik ( $\mathrm{g} \mathrm{cm}-3)$

$\% \mathrm{C}$ organik $\quad$ : menggunakan nilai persen karbon yang diperoleh dari hasil pangukuran di laboratorium.

Perhitungan Potensi Karbon

Potensi $\mathrm{C}$ tanah pada penggunaan lahan kering di Kecamatan Blang Bintang perlu dicari agar dapat mengetahui lebih lanjut mengenai nilai cadangan $\mathrm{C}$ yang terdapat pada setiap penggunaan lahan. Adapun langkah nya yaitu sebagai berikut (BSN, 2011) :

Potensi $\mathrm{C}=\mathrm{Ct} \times 100$

Keterangan :

Potensi C : kandungan $\mathrm{C}$ per hektar pada masing-masing penggunaan lahan dinyatakan dalam (toh ha-1)

$\mathrm{Ct} \quad$ : densitas $\mathrm{C}$ tanah, dinyatakan dalam gram $(\mathrm{g} \mathrm{cm}-2)$

100 : faktor konversi dari $\mathrm{g} \mathrm{cm}-2$ ke toh ha-1

\section{Analisis Data}

Data hasil analisis laboratorium yang berupa persen $\mathrm{C}$ dan nilai bulk density disajikan dalam bentuk total $\mathrm{C}$ didalam tanah yang selanjutnya dikonversi ke luas areal (hektar) sebagai potensi karbon. Potensi $\mathrm{C}$ tanah yang didapat selanjutnya dikonversi ke luas areal masingmasing penggunaan lahan dan dinyatakan sebagai cadangan $\mathrm{C}$ dalam ton ha-1, selanjutnya bandingkan cadangan karbon yang ada. 


\section{HASIL DAN PEMBAHASAN}

\section{Alang-alang}

Pengambilan sampel tanah pada penggunaan lahan alang-alang ini terletak di Desa Bira Cot Kecamatan Blang Bintang Kabupaten Aceh Besar. Berikut data hasil analisis karbon tanah pada penggunaan lahan alang-alang pada Tabel 1, yaitu:

Tabel 1. Bulk density, persen karbon, densitas karbon dan kriteria karbon tanah pada tipe penggunaan lahan Alang-alang

\begin{tabular}{|c|c|c|c|c|c|}
\hline \multirow{2}{*}{ No } & \multirow[b]{2}{*}{$\begin{array}{c}\text { Kedalaman } \\
(\mathbf{c m})\end{array}$} & \multicolumn{4}{|c|}{ Alang-alang } \\
\hline & & $\mathrm{BD}\left(\mathrm{g} \mathrm{cm}^{-1}\right)$ & $\% \mathrm{C}$ & $\begin{array}{c}\text { Densitas C } \\
\left(\mathrm{g} \mathrm{cm}^{-2}\right)\end{array}$ & Kriteria \\
\hline 1. & $0-5$ & 1,43 & 2,12 & 0,152 & Sedang \\
\hline 2. & $5-10$ & 1,43 & 1,91 & 0,137 & Sedang \\
\hline 3. & $10-20$ & 1,43 & 1,72 & 0,246 & Rendah \\
\hline 4. & $20-30$ & 1,54 & 1,26 & 0,194 & Rendah \\
\hline 5. & $30-70$ & 1,54 & 0,83 & 0,511 & Sangat rendah \\
\hline 6. & $70-100$ & 1,54 & 0,15 & 0,069 & Sangat rendah \\
\hline & Rata-rata & 1,48 & 1,33 & 0,218 & Rendah \\
\hline
\end{tabular}

Sumber: Hasil analisis laboratorium

Berdasarkan pada Tabel 6, dapat dilihat bahwa nilai \% C yaitu dari 0,15-2,12 \% dengan kriteria sedang, rendah hingga sangat rendah. Apabila diambil rata-rata, nilai $\mathrm{C}$ pada penggunaan lahan alang-alang ini memiliki kriteria rendah yaitu dengan nilai 1,33\%. Penggunaan lahan alang-alang ini memiliki nilai yang cukup tinggi, hal ini disebabkan karena tanah yang cukup subur dan kondisi lahan yang cenderung datar sehingga tidak mudah tererosi dan bahan organik tetap terakumulasi dengan baik pada tanah.

Penggunaan lahan alang-alang merupakan penggunaan lahan yang vegetasi alangalangnya cukup padat, hanya terdapat sedikit lahan yang kosong dari vegetasi alang-alang. Tanah pada penggunaan lahan alang-alang ini memiliki tekstur lempung berdebu, yang mana fraksi debu sedikit lebih mendominasi dari pada fraksi pasir dan liat. Perakaran alang-alang yang cukup banyak pada lapisan top soil menjadikan banyak terdapat $\mathrm{C}$ pada lapisan tersebut, hal ini dapat dilihat pada kedalaman 0-30 $\mathrm{cm}$ memiliki kriteria \% C yang rendah hingga sedang. Lapisan tanah pada kedalaman 30-100 cm merupakan lapisan yang sulit dijangkau oleh akar tanaman, sehingga pada lapisan tersebut akan lebih sedikit mengandung $\mathrm{C}$ tanah.

\section{Lahan Terbuka}

Pengambilan sampel tanah pada lahan terbuka ini terletak di desa Batee Meucap Kecamatan Blang Bintang Kabupaten Aceh Besar. Adapun hasil analisis karbon tanah yang terdapat pada lahan lahan terbuka disajikan pada Tabel 2. 
Tabel 2. Bulk density, persen karbon, densitas karbon dan kriteria karbon tanah pada tipe penggunaan lahan terbuka

\begin{tabular}{lccccc}
\hline \multirow{2}{*}{ No } & $\begin{array}{c}\text { Kedalaman } \\
(\mathbf{c m})\end{array}$ & BD $\left(\mathbf{g ~ c m}^{-\mathbf{1}}\right)$ & $\mathbf{\%} \mathbf{C}$ & $\begin{array}{c}\text { Densitas C } \\
\left(\mathbf{g ~ c m}^{-2}\right)\end{array}$ & Kriteria \\
\cline { 3 - 6 } & $0-5$ & 1,54 & 1,7 & 0,131 & Sedang \\
2. & $5-10$ & 1,54 & 1,08 & 0,083 & Sedang \\
3. & $10-20$ & 1,54 & 0,75 & 0,116 & Rendah \\
4. & $20-30$ & 1,57 & 0,51 & 0,080 & Rendah \\
5. & $30-70$ & 1,57 & 0,29 & 0,182 & Sangat rendah \\
6. & $70-100$ & 1,57 & 0,31 & 0,146 & Sangat rendah \\
\hline & Rata-rata & $\mathbf{1 , 5 5}$ & $\mathbf{0 , 7 7}$ & $\mathbf{0 , 1 2 3}$ & Sangat rendah \\
\hline
\end{tabular}

Sumber : Hasil analisis laboratorium

Berdasarkan hasil yang didapat pada Tabel 8, dapat dilihat bahwa \% C lahan terbuka memiliki kriteria sangat rendah sampai rendah. Hanya pada kedalaman 0-5 cm dan $5-10 \mathrm{~cm}$ yang memiliki kriteria rendah, sedangkan pada kedalaman selanjutnya memiliki kriteria sangat rendah dan nilai rata-rata $\mathrm{C}$ juga menunjukkan kriteria yang sangat rendah. Kriteria $\mathrm{C}$ yang rendah bisa disebabkan oleh banyak faktor, salah satunya yaitu erosi.

Menurut Vagen dan Winowieck (2013), pada umumnya erosi yang terjadi di lahan kosong dapat mengakibatkan stok SOC menjadi rendah. Dengan demikian kandungan C tanah pada penggunaan lahan terbuka akan berkurang apabila sering terjadinya erosi pada penggunaan lahan tersebut. Penggunaan lahan terbuka merupakan kawasan dengan lahan yang hampir tidak ditumbuhi oleh vegetasi, pada kawasan penelitian lahan terbuka yang diteliti merupakan lahan yang baru saja dibuka beberapa tahun terakhir.

\section{Potensi Karbon Tanah}

Potensi karbon tanah pada setiap penggunaan lahan memiliki nilai yang berbeda-beda, hal ini disebabkan oleh beberapa faktor seperti jenis tanah, jenis penggunaan lahan, kandungan hara, kandungan bahan organik, tekstur tanah dan lain sebagainya. Beberapa parameter yang diperlukan untuk mengetahui potensi karbon pada setiap penggunaan lahan yaitu seperti kedalaman pengambial sampel tanah, bulk density tanah dan yang terpenting yaitu hasil analisis kandungan \% $\mathrm{C}$ tanah yang didapat setelah dianalisis di laboratorium. Nilai potensi $\mathrm{C}$ didapat dari mengkonversi nilai densitas $\mathrm{C}$ ke dalam satuan berat (ton) dan luas areal (hektar) dan didapatlah nilai potensi $\mathrm{C}$ dalam satuan ton ha ${ }^{-1}$ pada setiap penggunaan lahan.

Berdasarkan hasil analisis pada Laboratorium Penelitian Tanah dan Tanaman Universitas Syiah Kuala, maka didapatlah potensi karbon tanah dari tujuh tipe penggunaan lahan yang terlihat pada Gambar 2 sebagai berikut: 


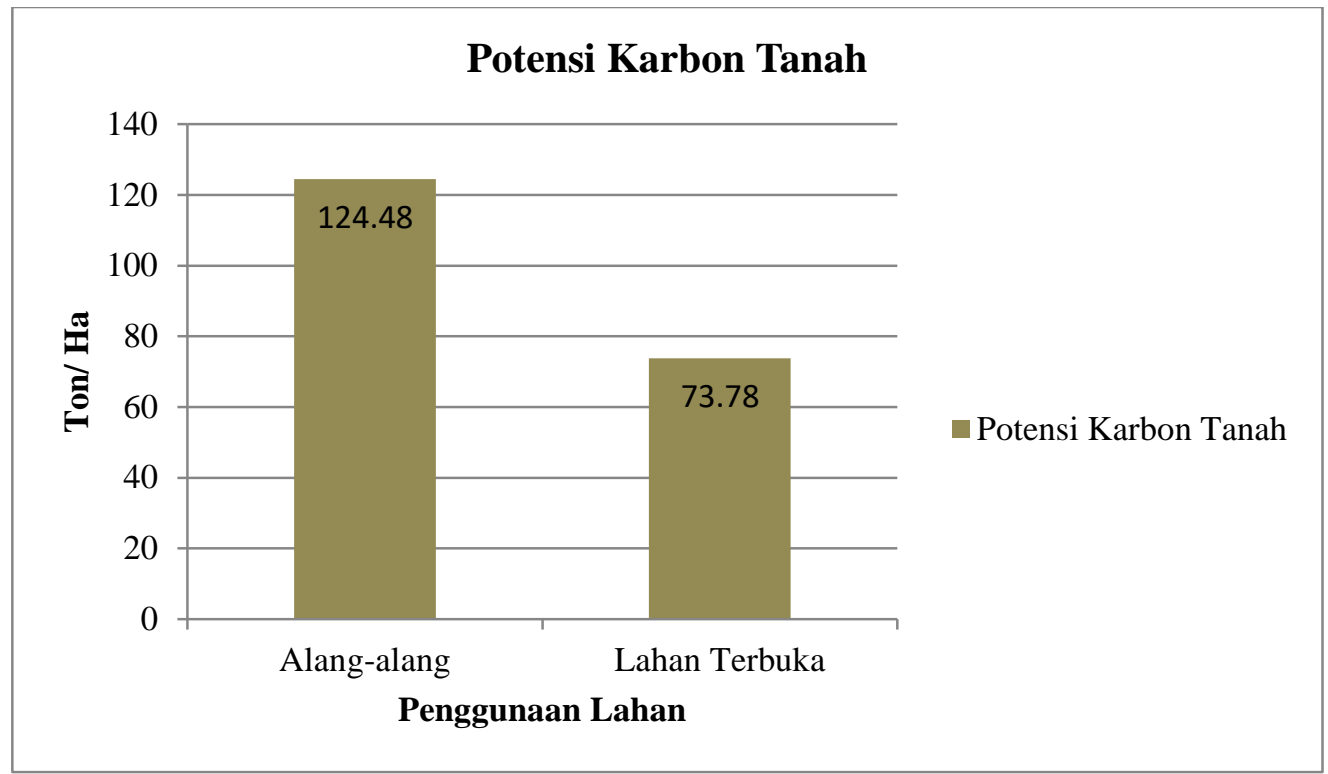

Berdasarkan Gambar 2 diatas, dapat dilihat nilai potensi $\mathrm{C}$ tanah pada tipe penggunaan lahan alang-alang dan lahan terbuka, pada gambar terlihat bahwa penggunaan lahan alangalang memiliki nilai yang lebih tinggi dari pada penggunaan lahan terbuka. Berdasarkan hasil penelitian Sufardi et al. (2020), menunjukkan bahwa kandungan karbon organik tanah di lahan kering di Kabupaten Aceh Besar bervariasi dari rendah sampai sangat tinggi $(0,23$ $3,95 \%$ ) tergantung jenis tanah (atau ordo tanah). Potensi $\mathrm{C}$ tanah pada beberapa tipe penggunaan lahan di kabupaten Aceh Besar khususnya Kecamatan Blang Bintang memiliki nilai yang beragam.

Yassir (2012) melaporkan bahwa kandungan karbon pada pada penggunaan lahan alang-alang di Kalimantan jauh lebih rendah daripada yang di Sumatera, hal ini dapat dilihat dari hasil penelitian yang pada kedalaman tanah 0-45 cm di Bukit Suharto Kalimantan Timur potensi $\mathrm{C}$ tanah pada penggunaan lahan alang-alang sebesar 40 ton $\mathrm{ha}^{-1}$. Apabila dibandingkan, potensi karbon yang terdapat pada penggunaan lahan alang-alang di Kecamatan Blang Bintang Kabupaten Aceh Besar lebih tinggi daripada yang ada di kawasan Bukit Suharto Kalimantan Timur, hal ini disebabkan karena pada kawasan penelitian di Kecamatan Balang Bintang C tanah diambil sampai kedalaman $100 \mathrm{~cm}$, sedangkan pada penelitian Yassir (2012) sampel tanah hanya diambil sampai kedalam $45 \mathrm{~cm}$ saja dan memiliki perbedaan kedalaman tanah sebesar $55 \mathrm{~cm}$.

Berdasarkan nilai potensi $\mathrm{C}$ yang didapat, maka kita dapat memperkirakan cadangan $\mathrm{C}$ tanah di Kecamatan Blang Bintang dengan cara mengalikan nilai potensi karbon tanah (ton $\mathrm{ha}^{-1}$ ) dengan luas area (ha). Berikut cadangan $\mathrm{C}$ tanah yang disajikan pada Tabel 3.

\begin{tabular}{llccc}
\hline No. & Land Utility Type & $\begin{array}{c}\text { Potensi karbon } \\
(\text { ton ha-1) }\end{array}$ & $\begin{array}{c}\text { Luas area } \\
\text { (ha) }\end{array}$ & $\begin{array}{c}\text { Cadangan karbon } \\
\text { (ton) }\end{array}$ \\
\hline 1. & Alang-alang & 124,48 & 16,75 & $2.085,04$ \\
2. & Lahan Terbuka & 73,78 & $1.040,43$ & $76.762,93$ \\
& Total & $\mathbf{1 9 8 , 2 6}$ & $\mathbf{1 . 0 5 7 , 1 8}$ & $\mathbf{7 8 . 8 4 7 , 9 7}$ \\
\hline
\end{tabular}


Berdasarkan luas area, lahan terbuka merupakan area yang paling luas yaitu 1.040,43 ha dengan nilai cadangan $\mathrm{C}$ sebesar 76.762,93 ton dan penggunaan lahan alang-alang hanya mempunyai luas sebesar 16,75 ha dengan nilai cadangan $\mathrm{C}$ sebesar 2.085,04 ton.

\section{Strategi Meningkatkan Karbon Tanah}

Menurut (Rachman et al., 2003), Beberapa hasil penelitian menunjukkan bahwa pengolahan tanah yang berlebihan menjadi penyebab utama terjadinya kerusakan struktur tanah. Sehingga diperlukan suatu sistem olah tanah yang lebih rasional terhadap kelestraian lingkungan. Secara komparatif, cadangan dan sekuestrasi karbon tertinggi berasal dari akumulasi bahan organik yang ada disekitar kawasan. Tanah yang berada dikawasan ini memiliki umur yang lama daripada tanaman lainnya, oleh karena itu dekomposisi terus menerus terjadi karena adanya akumulasi dan input organik dikawasan tersebut sehingga bisa menghasilkan karbon tertinggi baik berupa stok maupun sekuestrasi. Kendati demikian, pengelolaan tanah yang baik pada lahan kering dapat memainkan peran penting dalam pemeliharaan $\mathrm{C}$ tanah, perubahan iklim dan menjaga kualitas tanah.

Menurut Utomo (1995) dalam Yurres et al. (2014), salah satu alternatif pengolahan tanah yang dapat mempertahan kan produktivitas tanah yaitu dengan cara olah tanah konservasi. Olah tanah secara konservasi merupakan cara penyiapan lahan yang dalam penerapannya menyisakan sisa tanaman di atas permukaan tanah sebagai mulsa dengan tujuan untuk menekan erosi dan mengurangi penguapan air dari permukaan tanah. Selain sistem olah tanah, keberadaan bahan organik tanah memegang peranan penting pada pertumbuhan tanaman dan kesuburan tanah. Hal ini mengingat bahwa bahan organik tanah dapat mengendalikan berbagai proses penting dalam tanah, seperti memasok hara melalui perubahan status $\mathrm{C}$ dan $\mathrm{N}$ sebagai unsur utama bahan organik tanah, meningkatkan agregasi tanah, meningkatkan ketersediaan air tanah, dan mengurangi kehilangan hara pada tanah.

Kebutuhan untuk menstabilkan konsentrasi gas rumah kaca diatmosfer merupakan tantangan lingkungan yang besar di dunia. Dalam mengontrol konsentrasi ini, manusia dapat mengurangi emisi bahan bakar fosil dan/atau mengidentifikasi mekanisme untuk menghilangkan gas rumah kaca setelah diemisikan. Menurut Amundson dan Biardeau (2018), Saat ini, industri, transportasi, dan penggunaan rumah tangga mengeluarkan hampir $10 \mathrm{Gt} \mathrm{C}$ ke atmosfer setiap tahun, dan tidak ada harapan segera untuk pembalikan laju emisi yang drastis ini. Dengan demikian, penyerapan $\mathrm{CO}_{2}$ di atmosfer sebagai karbon organik di biosfer menarik perhatian sebagai cara alternatif untuk membantu membendung laju pertumbuhan gas rumah kaca dan perubahan iklim.

Menurut Melenya et al. (2015) penerapan input organik seperti mulsa, meningkatkan daur ulang keterikatan hara dan mineral serta efisiensi penggunaan pupuk, dapat memperbaiki sifat kimia, fisik dan juga mengurangi erosi pada tanah. Hasil penelitian (Juan Li et al., 2018), dengan jelas menunjukkan bahwa 26 tahun penambahan pupuk organik atau kombinasi dengan pupuk mineral menurunkan bulk density tanah secara signifikan, meningkatkan konsentrasi total SOC, stok SOC dan \% C tanah.

Adapun usaha-usaha rehabilitasi yang perlu dilakukan pada penggunaan lahan alangalang yaitu melakukan kegiatan agroforestry. Penggunaan lahan alang-alang merupakan kawasan dengan vegetasi alang-alang yang dominan, alang-alang memiliki perakaran rimpang (rizoma) yang tumbuh di tanah pada kedalaman 0-40 $\mathrm{cm}$, akar alang-alang tumbuhnya memanjang dan bercabang-cabang, karena kondisi vegetasi dan perakaran yang padat, maka 
tanah pada kawasan alang-alang memiliki kandungan $\mathrm{C}$ yang cukup tinggi, namun harus ditingkatkan lagi dengan berbagai strategi demi untuk meningkatkan $\mathrm{C}$ tanah dan upaya mitigasi perubahan iklim, hal-hal yang direkomendasikan dalam upaya peningkatan $\mathrm{C}$ tanah pada penggunaan lahan alang-alang yaitu pengolahan tanah konservatif dan agroforesry. Agroforestry merupakan hal yang harus dilakukan guna untuk menjadikan kawasan tersebut dipenuhi oleh tanaman berukuran kecil, sedang dan besar yang dapat menjadikan lahan alangalang lebih produktif, subur dan memiliki kandungan $\mathrm{C}$ tanah yang lebih banyak.

Lahan terbuka merupakan penggunaan lahan yang hampir tidak memiliki vegetasi, oleh karena itu, rekomendasi yang sesuai untuk peningkatan $\mathrm{C}$ pada lahan terbuka yaitu, reboisasi dan agroforestry. Reboisasi pada lahan terbuka sangat perlu dilakukan agar tanah tidak tererosi dan juga dapat mengikat air dan hara. Apabila pada lahan terbuka terdapat tanaman, maka akar dari tanaman tersebut akan dapat menahan tanah agar tidak mudah tererosi dan air hara yang ada dalam tanah bisa terjaga. Selanjutnya agroforestri dilakukan agar penggunaan lahan terbuka menjadi lebih produktif dan menghasilkan sumber pangan papan dan sandang dalam menunjang segala aktifitas makhluk hidup yang ada di muka bumi.

\section{KESIMPULAN DAN SARAN}

Persen Karbon (\% C) tanah tergolong dari kriteria sangat rendah hingga tinggi yaitu berkisar antara 0,15-2,12\%. Dari dua tipe penggunaan lahan, potensi karbon tanah pada penggunaan lahan alang-alang memiliki nilai yang paling tinggi yaitu 124,48 ton ha-1 dan lahan terbuka 73,78ton ha-1 yang memiliki nilai yang rendah. Cadangan $\mathrm{C}$ tanah yang terdapat di dua areal lahan kering Kecamatan Blang Bintang yaitu sebesar 78.847,97 ton. Penggunaan lahan terbuka memiliki nilai yaitu sebesar $76.762,93$ ton dan penggunan lahan alang-alang memiliki nilai yang rendah yaitu sebesar 2.085,04 ton. Upaya yang dapat dilakukan untuk meningkatkan kandungan dan potensi $\mathrm{C}$ yang ada di Kecamatan Blang Bintang Kabupaten Aceh Besar, yaitu pengolahan tanah konservatif, pengelolaan hara terpadu, penyisipan bibit pohon, agroforestry dan pemberian pupuk organik.

\section{DAFTAR PUSTAKA}

Amundson, R \& Biardeau, L. 2018. Soil carbon sequestration is an elusiveclimate mitigation tool.Proc.Natl.Acad.Sci.U.S.A.115,1165211656.www.pnas.org/cgi/doi/10.1073/pnas. 19 08917116. Diakses 18 Oktober 2020.

Brady. NC and Weil. 2008. The Nature and Properties of Soil. 14th Edition Pearson Educational Internasional, New Jersey. 965p.

Edwin M,. 2016. "Penilaian Stok Karbon Tanah Organik pada Beberapa Tipe Penggunaan Lahan Di Kutai Timur, Kalimantan Timur”. Jurnal Agrifo. Vol. 15. No. 2.

Hairiah, K., Rahayu, S. 2007. Pengukuran Karbon Tersimpan di Berbagai Macam Penggunaan Lahan. Bogor. World Agroforestry Centre - ICRAF, SEA Regional Office. University of Brawijaya, Indonesia.

Li J, Guo Z, Han J, Xu Y, Wang X. 2018. Effects of long-term fertilization on soil organik carbon mineralization and microbial community structure. Environment Research Council. Plos One 14(1): e0211163.

Melenya C, Bonsu M, Logah V, Quansah C, Adjei-Gyapong T, Yeboah IB, Tuffour HO, Abubakari A (2015) Carbon sequestration in soils under different land use systems and it impact on climate change. Appl Res J 1 (3): 164-168.

Rahmah F., Basri, H \& Sufardi, S. 2015. Potensi Karbon Tersimpan pada Lahan Margrove dan Tambak di Kawasan Pesisir Kota Banda Aceh. Jurnal Manajemen Sumberdaya 
Lahan, 4 (1), 527-534. http://www.jurnal.unsyiah.ac.id/MSDL/article/view/7124. Diakses tgl 13 oktober 2020.

Ruddiman, W. 2007. Losses of soil carbon Plows, Plagues, and Petroleum: How Humans Took Control of Climate. Princeton, NJ: Princeton University Press. 202p.

Sufardi, Arabia. T, Khairullah, Karnilawati dan Fuadi. Z. 2020. Distribution of carbon and soil quality in drylands of Aceh Besar, Indonesia. Article in IOP Conference Series Earth and Environmental Science, IOP publishing 458 (2020) 012040.https://iopscience.iop.org/article/10.1088/1755-1315/458/1/012040. diakses 13 Oktober 2020.

Syam'ani, Agustina. R, Susilawati, Nugroho, N. 2012. Cadangan karbon diatas permukaan tanah pada berbagai sistem penutupan lahan di sub-sub das amandit. ISSN 1412-4645. Jurnal hutan tropis volume 13 no. 2.

Utomo (1995) dalam Wibowo, Y S. Buchari, H. Arief, S. \& Utomo, M. 2014. Pengaruh sistem olah tanah pada lahan alang-alang (Imperata cylindrica) terhadap biomassa karbon mikroorganisme tanah (C-mik) yang ditanamai kedelai (Glycine max L.) musim kedua. J. Agrotek Tropika. ISSN 2337-4993 Vol. 2, No. 1: 149 - 154.

Utomo. M, Sudarsono, Rusman. B, Sabrina. T, Lumbanraja. J dan Wawan. 2016. Ilmu Tanah : Dasar-dasar dan Pengelolaan. Prenadamedia Group, Jakarta.

Van Noordwijk M; C. Cerri; PL. Woomer; K. Nugroho; and M. Bernoux. 1997. Soil carbon dynamics in the humid tropical forest. Elsevier. Geoderma Journal, 79: 187-225.

Yassir. I. 2012. Soil organic carbon stocks and changes upon forest regeneration in East Kalimantan-Indonesia. $\mathrm{PhD}$ Thesis. Wageningen University. Wageningen, The Netherlands. 